\title{
PGPR mediated Zinc biofertilization of soil and its impact on growth and productivity of wheat
}

\author{
G. Sirohi ${ }^{1,3}$, A. Upadhyay ${ }^{1 \#}$, P. Shankar Srivastava ${ }^{2}$ and S. Srivastava ${ }^{1 *}$ \\ ${ }^{1}$ Department of Genetics, Universwity of Delhi South Campus, New Delhi-110021. ${ }^{2}$ Department of \\ Biotechnology, Jamia Hamdard, New Delhi- 110062. ${ }^{3}$ National Institute of Plant Genome Research, New \\ Delhi-110067, India. *Corresponding author: sslab222012@gmail.com \#equal contribution
}

\begin{abstract}
Objectives: This study describes Zinc biofortification of wheat using a rhizospheric isolate, Pseudomonas fluorescens strain Psd.

Methods: The strain was used as a bio-ionculant in soil deficient in zinc and the plant-growth promoting potential and biofortification was assessed using a number of physical and biochemical parameters. The enzymatic studies indicated towards the zinc supply mediated by the strain

Result: This plant-growth-promoting strain, apart from the $\mathrm{Zn}$ accumulation potential, has the ability to solubilise $\mathrm{Zn}$ and was also able to leach out $\mathrm{Zn}$ from ore-tailings. The application of a $\mathrm{Zn}$-laden biomass of the strain in soil resulted in increased growth and productivity of wheat crop as demonstrated by pot experiments. The beneficial effect was also reflected in increased activities of some enzymes. In addition, grain $\mathrm{Zn}^{2+}$ content was enhanced by $\sim 85 \%$ in comparison to wheat grown in $\mathrm{Zn}^{2+}$-deficient soil.
\end{abstract}

Keywords: Biofortification, Zinc, plant-growth-promoting rhizobacteria, biofertilization

\section{Introduction}

Zinc is a crucial micronutrient for all life forms. In plants, it is involved in a wide array of metabolic processes like carbohydrate, lipid, protein and nucleic acid synthesis and degradation. Zinc is structurally bound to some important plant enzymes, like carbonic anhydrase and superoxide dismutase, the activities of which are negatively affected under zinc-deficient conditions (Hacisalihoglu et al. 2003). Zinc deficiency is prominently encountered in plants growing in calcareous and sodic soils due to the formation of insoluble zinc carbonate which decreases the availability of this metal (Hafeez et al. 2013). Major crops affected by zinc deficiency include wheat, rice, maize, cotton and citrus (Rashid and Ryan 2008).

Plant growth promoting rhizobacteria (PGPR) have been known for long to be involved in plant growth promotion via mechanisms such as phytohormone 
production, suppression of plant diseases and improved nutrient acquisition by nitrogen fixation, phosphate solubilization and metal accumulation (MartínezViveros et al. 2010, Upadhyay and Srivastava 2010). Apart from this, PGPR are also known to be key players in bioremediation of contaminated soils due to their ability to accumulate metals (Zhuang et al. 2007). Thus, the metal-laden PGP rhizobacterial biomass aids in the establishment of plants in metalcontaminated soils. Also, this biomass can serve as a bioinoculant in metal-deficient soils, sufficing for the requirement of essential metals as shown for Zinc by Whiting et al. (2001) and for nickel by Abou-Shanab et al. (2003).

Pseudomonas fluorescens strain Psd has been earlier characterized to possess multiple plant-growth promoting and biocontrol properties (Upadhyay and Srivastava 2008, 2010. We have also characterized zinc biosorption by this strain (Upadhyay and Srivastava 2014) In the present communication, we demonstrate the zinc biofertilization potential of this strain and its impact on the growth and development of wheat crop.

\section{Materials and Methods}

\subsection{Organism, culture conditions and metal source}

The PGPR strain used in this study is Pseudomonas fluorescens strain Psd which was originally isolated from the roots of Vigna mungo and characterised by Upadhyay and Srivastava (2008). For plant experiments, a variant of strain Psd tagged with lacZ through a mini-Tn5, namely, PsdLacZ was used in order to ease the selection of the desired strain from a heterogenous soil population. Bacterial suspension was prepared by raising the culture of PsdLacZ in
Gluconate Minimal medium (Gilotra and Srivasatva, 1997) in a Controlled Environment Shaker Incubator (Kühner, Switzerland) at $30^{\circ} \mathrm{C}$ and $200 \mathrm{rpm}$ for the required period of time.

The $\mathrm{Zn}^{2+}$ sources used for the experiments were autoclaved metal salt solution of $\mathrm{ZnSO}_{4} \cdot 7 \mathrm{H}_{2} \mathrm{O}$ and ore tailings procured from Regional Research Laboratory, Bhubaneshwar, India. For in vitro solubilization assay, $\mathrm{ZnO}$ was used. Cells were grown in the presence of different sources of Zinc for different times as per the requirement of the experiment.

\subsection{In vitro assessment of Zinc solubilization}

\subsubsection{Plate assay}

Qualitative assay for $\mathrm{ZnO}$ solubilization was performed as per the protocol of Fasim et al. (2002). Ten microlitre culture of $P$. fluorescens strain Psd was spotted on Tris minimal agar plates substituted with $14 \mathrm{mM} \mathrm{ZnO}$ and containing glucose as the carbon source. The plates were incubated at $30{ }^{\circ} \mathrm{C}$ for 14 days to see the solubilization efficiency. The control consisted of the same medium supplemented with $14 \mathrm{mM} \mathrm{ZnO}$ with gluconate as carbon source.

\subsubsection{Broth assay}

Broth assay for $\mathrm{ZnO}$ solubilization was done according to the protocol of Saravanan et al (2003). Solubilization was monitored for 4 weeks by measuring the amount of $\mathrm{Zn}^{2+}$ in the cell free supernatant.

\subsubsection{Zinc leaching from low-grade ore tailings}

Low grade ore tailings ( $20 \%$ pulp density) were suspended in distilled water for $24 \mathrm{~h}$ followed by 
addition of a carbon source (gluconate $0.4 \% \mathrm{w} / \mathrm{v}$ ). Ten millilitre and twenty millilitre culture biomass of strain Psd (corresponding to approx. 6mg and $12 \mathrm{mg}$ dry weight, respectively) was added to this suspension and $\mathrm{Zn}$ removal from ore suspension was monitored till 10 days.

\subsubsection{Estimation of $\mathrm{Zn}^{2+}$}

Samples for $\mathrm{Zn}^{2+}$ analysis were acid-digested using a mixture of $\mathrm{HNO}_{3}$ and $\mathrm{HClO}_{4}$ in 6:1 ratio. $\mathrm{Zn}^{2+}$ was estimated from appropriate dilutions of the digested samples using the Atomic Absorption Spectrophotometer (PerkinElemer model AAnalyst $400)$ at $219.86 \mathrm{~nm}$.

\subsection{Plant experiments}

\subsubsection{Experimental setup}

In order to look at the $\mathrm{Zn}$ biofertilization ability of P. fluorescens strain Psd, Triticum aestivum var. HD2851 was taken as an experimental crop. The seeds were procured from Indian Agricultural Research Institute (IARI), New Delhi, India. Soil used in this study was low-zinc soil $\left(\mathrm{Zn}^{2+} \sim 3 \mathrm{ppm}\right)$ obtained from a wheat field in Sonipat, Haryana, India, which falls under most zinc deficient areas in India. The experiment was performed in 8-inch earthen pots in two different sets. In the first set, $500 \mathrm{~g}$ soil was added to the pots and in second set, pots were filled with the mixture of soil and oretailings in the ratio 4:1 (Table 1).

Wheat Seeds were surface sterilized with $0.1 \%$ $\mathrm{HgCl}_{2}$ for $5 \mathrm{~min}$ followed by 3-4 times washing with autoclaved distilled water. Sterilized seed were inoculated with strain Psd grown in presence of $2 \mathrm{mM}$ $\mathrm{ZnSO}_{4} .7 \mathrm{H}_{2} \mathrm{O}$ for $24 \mathrm{~h}$ for the first set. For the second set, wheat seeds were inoculated with the bacterial cells grown in GMM basal medium for $24 \mathrm{~h}$.

A talc based carrier formulation was prepared by modification of the protocol suggested by Vidhyasekaran and Muthamilan (1995). For preparation of $80 \mathrm{~g}$ carrier formulation, $50 \mathrm{~g}$ of talc was mixed with $20 \mathrm{~mL}$ bacterial suspension $\left(\sim 10^{8} \mathrm{cfu} / \mathrm{mL}\right)$ followed by addition of $1 \mathrm{~mL}$ Carboxymethyl cellulose $(0.1 \% \mathrm{w} / \mathrm{v})$ and $1 \mathrm{~mL}$ Glycerol (50\% v/v).

\subsubsection{Strain survivability in vivo}

Periodic assessment for survival of $P$. fluorescens strain Psd in soil under environmental conditions was performed during the months of November, 2012 to February, 2013 using enumeration by plating $(\mathrm{cfu} / \mathrm{mL})$ the soil suspension on LB agar medium containing Kanamycin $(50 \mu \mathrm{g} / \mathrm{mL})$, Chloramphenicol $(50 \mu \mathrm{g} / \mathrm{mL}), \quad$ Cycloheximide $(50 \mu \mathrm{g} / \mathrm{mL})$ and X-gal $(40 \mu \mathrm{g} / \mathrm{mL})$. Blue colonies obtained upon overnight incubation at $30{ }^{\circ} \mathrm{C}$ were taken into account as strain Psd.

\subsubsection{Growth parameters}

Three plants were uprooted during $3^{\text {rd }}$ and $6^{\text {th }}$ weeks after sowing for measurement of physical parameters such as root and shoot length along with their respective fresh and dry weights. Root and shoot of the plants were separated by cutting with scissor and weighed individually for their fresh weight and drying after drying at $70{ }^{\circ} \mathrm{C}$ for $72 \mathrm{~h}$. 
Table 1. Scheme of the experimental setup

\begin{tabular}{|c|l|c|l|}
\hline \multicolumn{2}{|c|}{ Set 1 } & \multicolumn{2}{c|}{ Set 2 } \\
\hline Set code & \multicolumn{1}{|c|}{$\begin{array}{c}\text { Experimental details } \\
\text { (Low-Zn soil filled in pots) }\end{array}$} & Set code & \multicolumn{1}{c|}{$\begin{array}{c}\text { Experimental details } \\
\text { (Mixture of Low-Zn soil and Zn } \\
\text { ore in 4:1 ratio) }\end{array}$} \\
\hline la & $\begin{array}{l}\text { Seeds inoculated with strain } \\
\text { PsdLacZ grown in 2mM Zn }\end{array}$ & 2a & $\begin{array}{l}\text { Seeds bacterized with strain } \\
\text { PsdLacZ grown in minimal }\end{array}$ \\
\hline lb & $\begin{array}{l}\text { Seeds coated with carrier } \\
\text { containing PsdLacZ grown } \\
\text { in 2mM Zn }\end{array}$ & $2 b$ & $\begin{array}{l}\text { Seeds coated with carrier having } \\
\text { Strain PsdLacZ }\end{array}$ \\
\hline lc & $\begin{array}{l}\text { Carrier along with PsdLacZ } \\
\text { grown in 2mM Zn mixed } \\
\text { with soil (10\% w/w) }\end{array}$ & 2c & $\begin{array}{l}\text { Carrier mixed with soil } \\
\text { (10\% w/w) }\end{array}$ \\
\hline C1 & Uninoculated soil & C2 & $\begin{array}{l}\text { Uninoculated soil and Zn ore } \\
\text { (mixed in 4:1 ratio) }\end{array}$ \\
\hline
\end{tabular}

\subsubsection{Biochemical studies}

Biochemical assays were performed at 3-week intervals till $9^{\text {th }}$ week after sowing of seeds. Total Chlorophyll content was estimated in fresh leaves according to the protocol of Arnon (1949). Nitrate reductase (NR) assay was performed using leaf discs as per the protocol given by Jaworski (1971). For enzyme assays, $100 \mathrm{mg}$ leaf samples were weighed and homogenised in pre-chilled extraction buffer containing sodium phosphate buffer $(0.1 \mathrm{M})$, EDTA $(0.4 \mathrm{mM})$, PMSF $(1 \mathrm{mM})$, DTT $(2 \mathrm{mM})$, glycerol $(10 \%), \mathrm{MgCl}_{2}(5 \mathrm{mM})$, HEPES (50mM, pH 7.5) and PVP (1\%). The homogenate was transferred to 2 $\mathrm{ml}$ Eppendorf tubes and centrifuged at 10,000 rpm for $20 \mathrm{~min}$ at $4{ }^{\circ} \mathrm{C}$. Supernatant was transferred to fresh tubes and the extract was used for different enzyme assays. Protein Content in the extracts was determined using BCA kit (Sigma Aldrich, USA). The presence of certain $\mathrm{Zn}$-containing enzymes, namely,
Carbonic anhydrase (CA), Superoxide dismutase (SOD) and Alkaline phosphatase (AP) was assessed using the protocols of Smith and Ferry (2000), Kakkar et al. (1984) and Gugi et al (1991), respectively. Similarly, the activities of anti-oxidant enzymes, Glutathione reductase (GR) and Peroxidase (POD), were determined according to the protocols of Rao et al (1996) and Reddy (1998).

\subsubsection{Zinc analysis of soil and plant parts}

Periodic assessment of available soil zinc in both the sets was done by preparing a soil suspension containing $1 \mathrm{~g}$ soil in $1 \mathrm{~mL}$ deionised water followed by fileration to remove soil particles. The resulting suspension was then analysed for $\mathrm{Zn}^{2+}$ using AAS. For determination of $\mathrm{Zn}^{2+}$ content in plant parts, the root (50mg dry weight) and shoot (50mg dry weight) were separately acid-digested and were taken forward for $\mathrm{Zn}^{2+}$ estimation. 


\subsubsection{Seed analysis}

After completion of the life-cycle of plant, seeds were harvested and carried forward for quantitative and qualitative analysis. Biomass of the seeds was obtained by weighing 10 seeds/pot. The biochemical parameters such as $\mathrm{Zn}^{2+}$ content, total soluble protein and reducing carbohydrate levels were also analysed. In addition, the elemental analysis in terms of carbon, hydrogen and nitrogen content of seeds was performed using the CHN Analyser (Vario El Cube, Elementar, Germany).

\subsubsection{Statistical analysis}

Values reported in this paper are presented as the mean of three replicates. Data were tested at a significance level of $P<0.05$ using one-way ANOVA followed by Dunnett's $\mathrm{t}$ test and expressed as mean $\pm \mathrm{SD}$.

\section{Results}

\subsection{Zinc solubilization in vitro}

Zinc solubilization potential of $P$. fluorescens strain Psd was indicated by a clear zone around the bacterial growth on plate substituted with $14 \mathrm{mM}$ $\mathrm{ZnO}$ (Figure 1A). The solubilization was further confirmed by broth assay, wherein, a consecutive increase in available $\mathrm{Zn}^{2+}$ in the medium substituted with $12 \mathrm{mM} \mathrm{ZnO}$ was observed till the $4^{\text {th }}$ week in the presence of glucose as the carbon source (Figure 1B). This process was also accompanied by a drop in $\mathrm{pH}$ to $\sim 5.0$ in the medium containing glucose. The $\mathrm{pH}$ of uninoculated control and gluonatecontaining medium, however, was maintained at 7.0 and 8.0 , respectively.

\subsection{Zinc leaching from low-grade ore tailings}

Leaching of $\mathrm{Zn}$ from ore tailings was observed by a drop in $\mathrm{Zn}^{2+}$ after $4^{\text {th }}$ day of bacterial inoculation. Since, no acid-digestion was used to catalyse metal removal, the increase in solubilized $\mathrm{Zn}$ till $4^{\text {th }}$ day was obtained due to spontaneous $\mathrm{Zn}$ release and any accumulation by the cells during this period was not significant. As indicated in Figure 1C, $10 \mathrm{~mL}$ culture biomass (corresponding to $\sim 8 \mathrm{mg}$ dry weight) of $P$. fluorescens strain Psd led to $\sim 27 \%$ decrease in $\mathrm{Zn}^{2+}$ content of the ore suspension after 10 days of exposure.

\subsection{Plant experiments}

\subsubsection{Survival of strain in external environment}

The survivability of the $P$. fluorescens strain Psd was followed for 10 weeks after inoculation in soil. In the presence of bacterial carrier formulation, 40\% survival was obtained till $10^{\text {th }}$ week as compared to $\sim 23 \%$ survival in case of direct bacterial inoculation in soil (Table 1).

\subsubsection{Effect on growth of wheat crop}

The effect of $\mathrm{Zn}$ biofertilization of soil by strain Psd on growth and development of wheat was studied by assessing various parameters. Initially, seed germination was observed after 6 days of sowing. The deficiency of $\mathrm{Zn}$ in soil affected seed germination which was only $42-45 \%$ in untreated control. On the other hand, fortification of soil by Zn-grown P. fluorescens strain Psd (Psd-Zn) led to increased percent germination, which varied within the experimental sets. As is indicated, $100 \%$ 
seed germination was obtained in soil mixed with bacterial carrier formulation. This was followed by $80-90 \%$ germination of seeds coated with the carrier and approximately $70-80 \%$ germination in case of seeds inoculated with strain Psd-Zn (Figure 2A). In addition, in controls, slow emergence of seedling was also observed compared to inoculated seeds. Comparative analysis of morphological parameters, such as length of root and shoot and their respective biomasses, also indicated towards a better growth of plants growing in soil supplemented with zinc-laden Psd biomass (Figure 2 B-E \& Figure 3 A-B). Apart from this, tillering was observed at $6^{\text {th }}$ week in the plants growing in soil supplemented with Psd-Zn while no tillers were found in untreated control plants at this stage (Figure 3B).

(a)

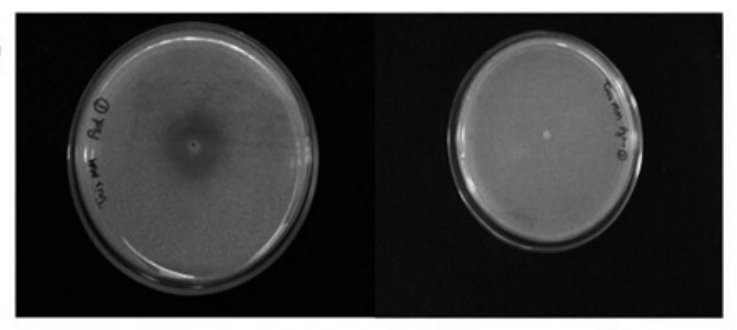

(b)

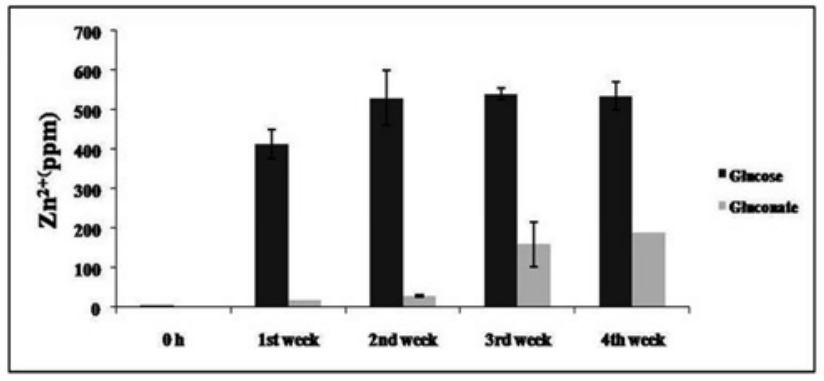

(c)

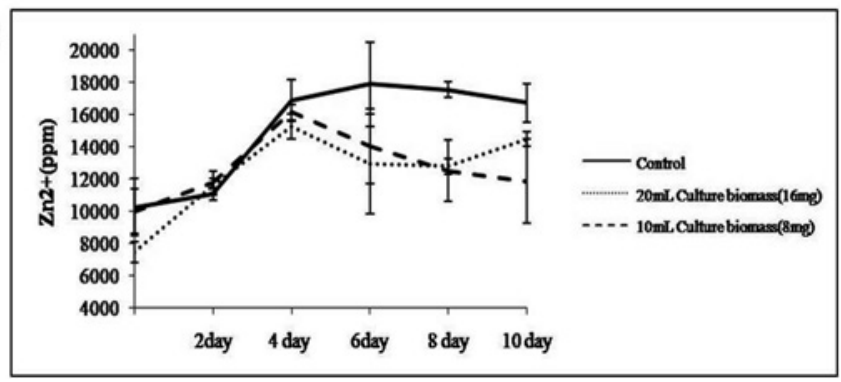

Figure 1. In vitro zinc oxide solubilization and Zinc ore leaching by P. fluorescens strain Psd. (A) Plate assay showing a clear zone near the inoculated region (image on the right is negative control) (B) Quantification of zinc solubilization indicated by increase in available zinc over time (C) Zinc status of ore suspension inoculated with Psd indicative of leaching of zinc by the bacterial strain 
(a)
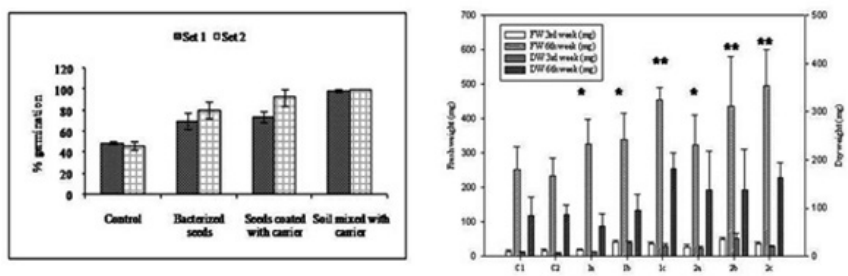

(c)

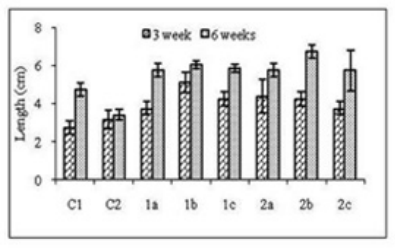

(d)

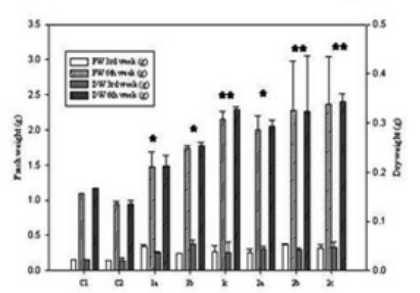

(e)

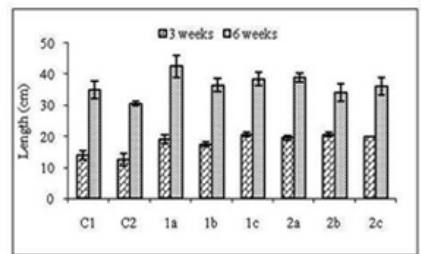

Figure 2: Assessment of growth and biomass of plants (A) percent seed germination; (B) root biomass; (C) root length; (D) shoot biomass and $(E)$ shoot length. $\{* * *$ indicates $P<0.001$, ** indicates $P<0.01 \& *$ indicates $P<0.05$ versus controls (C1 and C2)\}

\subsection{Effect on total Chlorophyll and protein content}

No significant difference in total chlorophyll and protein content was observed between control and treated sets (data not shown). However, an agedependent increase in total chlorophyll was found in all the plants while no such variation was observed in the case of protein levels.

\subsection{Quantification of Nitrate reductase (NR) activity}

Comparison of the nitrate reductase activity between Psd-Zn fortified plants and controls showed that
$\mathrm{Zn}^{2+}$ supply led to a drop in NR activity in wheat, the activity being maximum in control plants. Apart from this, a decline in activity was obtained with time (Figure $4 \mathrm{~A}$ ).

\subsection{Estimation of anti-oxidant enzymes}

The activities of anti-oxidant enzymes, Glutathione reductase (GR) and Peroxidase (POD), were determined in Psd treated sets as well as controls. Different levels of these enzymes were detected as the plants progressed from $3^{\text {rd }}$ to $9^{\text {th }}$ week (Figure $4 \mathrm{~B} \& \mathrm{C})$. 


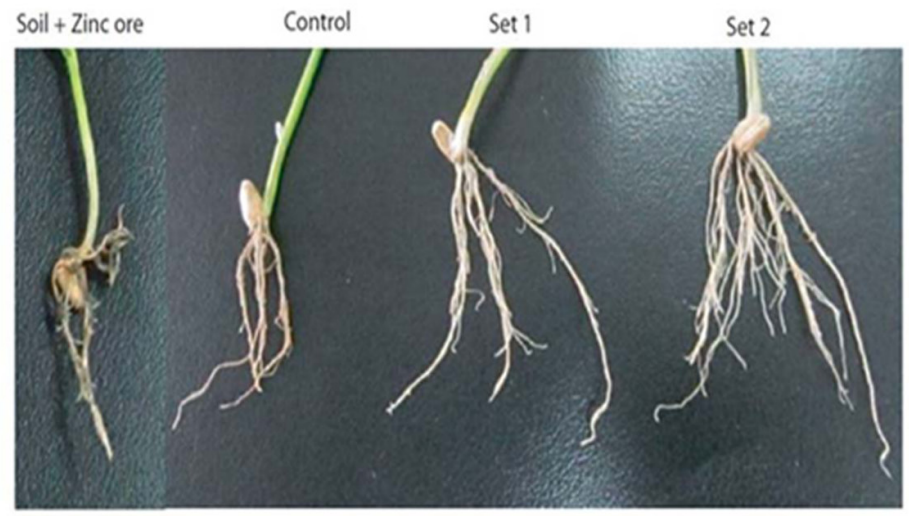

(a)

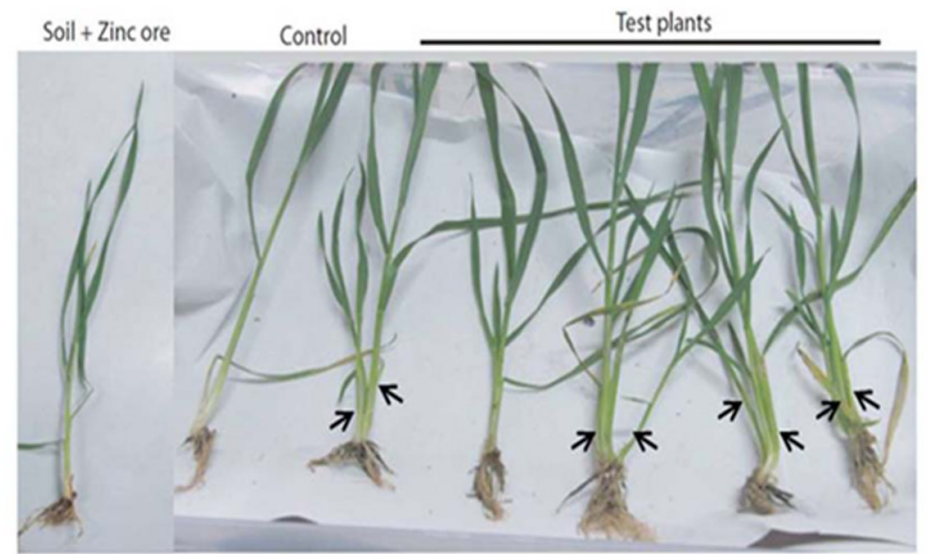

(b)

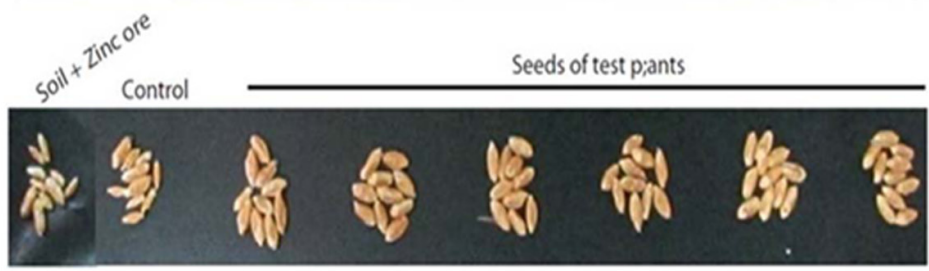

Figure 3. Morphological study of plants. (A) root phenotype (B) tillering status (shown by arrows) (C) seed morphology 
(a)

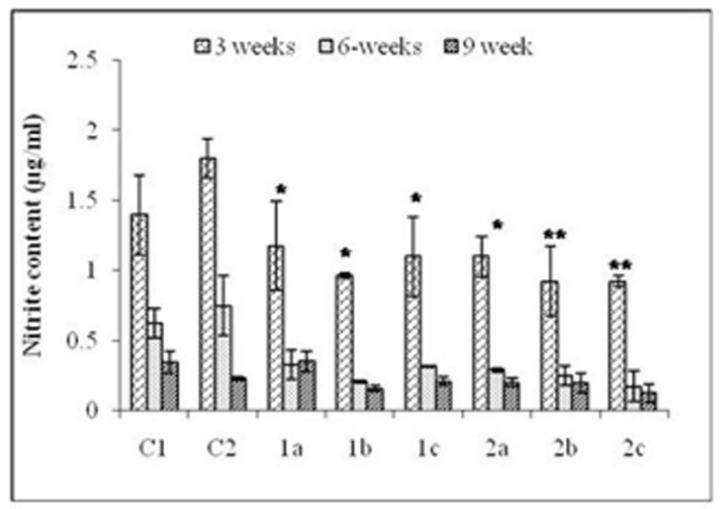

(b)

(c)
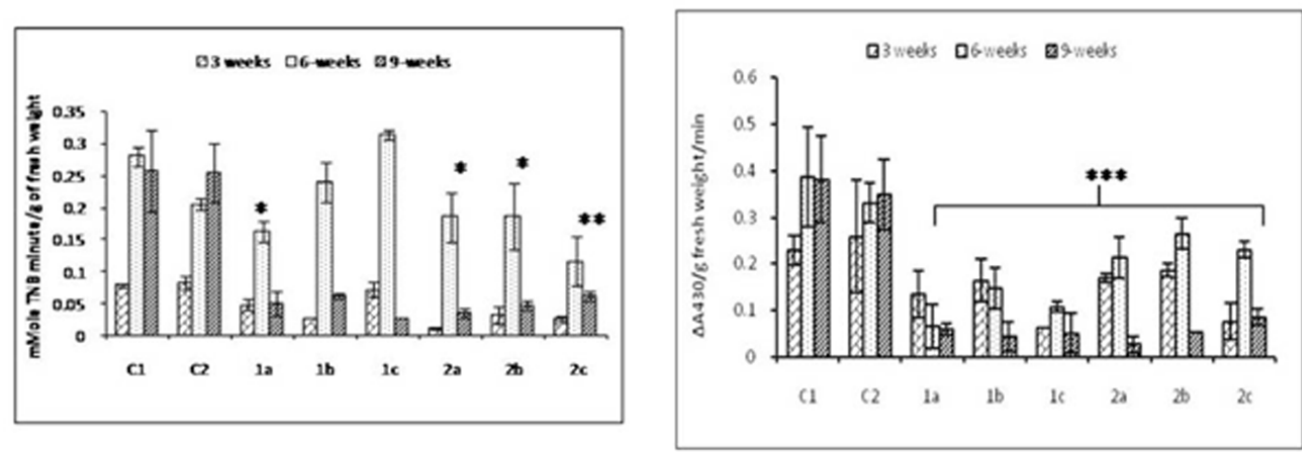

Figure 4: Assessment of (A) Nitrate reductase; (B) Glutathione reductase and ; (C) Peroxidase activities \{*** indicates $P<0.001$, ** indicates $P<0.01 \&$ * indicates $P<0.05$ versus controls $(\mathrm{C} 1$ and $\mathrm{C} 2)\}$

\subsection{Activity of enzymes with Zn as co-factor}

A progressive increase in CA activity was obtained in all sets. But the activity was prominently higher for plants growing in Psd-inoculated soil as compared to plants growing in uninoculated soil (Figure 5A). Low levels of superoxide dismutase activity, measured in terms of inhibition in reduction of NBT, were obtained in control sets. On the other hand, increase in SOD activity of upto 20-folds in $6^{\text {th }}$ week was detected in Psd-treated sets (Figure 5B). In addition alkaline phosphatase was also estimated containing zinc as co-factor and the activity 
of this enzyme was also obtained higher in treated plants compared to untreated controls (Figure 5C).

\subsection{Zinc analysis of soil and plant parts}

Estimation of Zinc released in soil for set 1 and solubilization of $\mathrm{Zn}$ ore in soil for set 2 by $P$. fluorescens strain Psd was confirmed by analysing the $\mathrm{Zn}^{2+}$ status of soil suspension till 6-weeks after inoculation (data not shown). Since the soil used for the experiments was low in $\mathrm{Zn}^{2+}$ content and the $\mathrm{Zn}^{2+}$ from ore-tailings was in an unavailable form, the control sets showed negligible levels of the metal. The treated sets, however, displayed approximately 100 -fold increase in $\mathrm{Zn}^{2+}$ content (data not shown). This was more prominent in set 2 soil, since the $\mathrm{Zn}^{2+}$-source in this set was a lowgrade ore tailing and any resultant increase in $\mathrm{Zn}^{2+}$ content is indicative of solubilization mediated by the strain. Apart from monitoring the soil suspension, $\mathrm{Zn}^{2+}$ levels were also followed in the uprooted plant parts like leaf and root till 6 weeks (Figure 5D). The application of Zn-laden bacterial biomass also aided in enhancing the $\mathrm{Zn}^{2+}$ content of plant parts, the increase in root $\mathrm{Zn}^{2+}$ being more apparent than shoot.

(a)

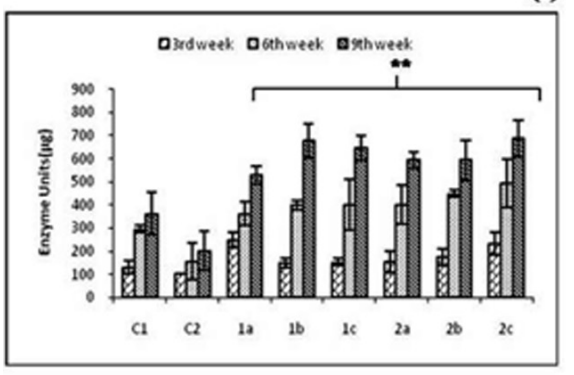

(b)

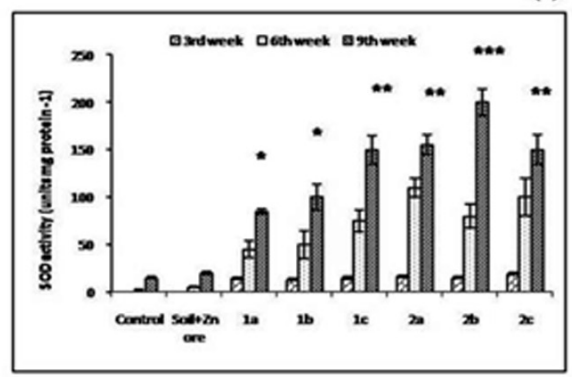

(c)

(d)
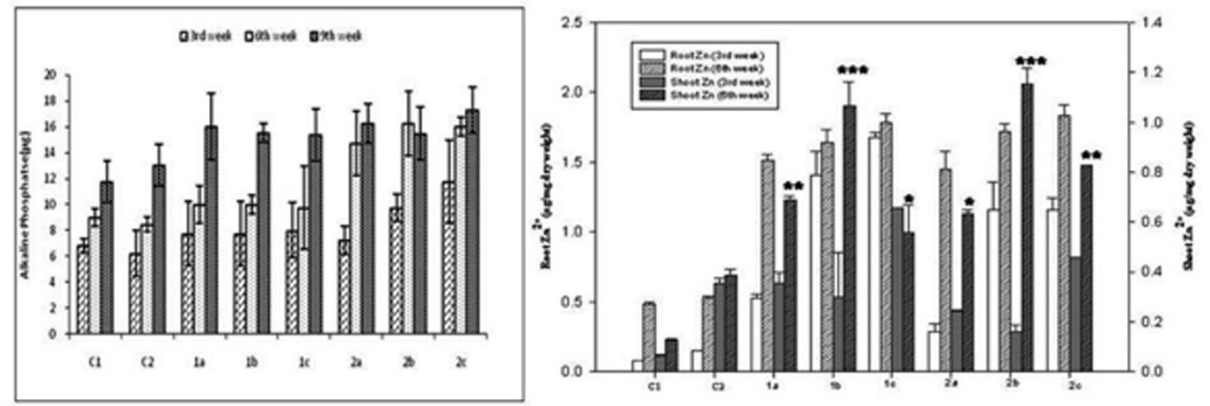

Figure 5. Quantification of the activity of enzymes containing zinc as co-factor. (A) Carbonic anhydrase; (B) Super oxide dismutase and (C) alkaline phosphatase (D) $\mathrm{Zn}^{2+}$ status of roots and shoots $\{* * *$ indicates $P<0.001$, ** indicates $P<0.01 \&$ * indicates $P<0.05$ versus controls $(\mathrm{C} 1$ and $\mathrm{C} 2)\}$ 
(a)

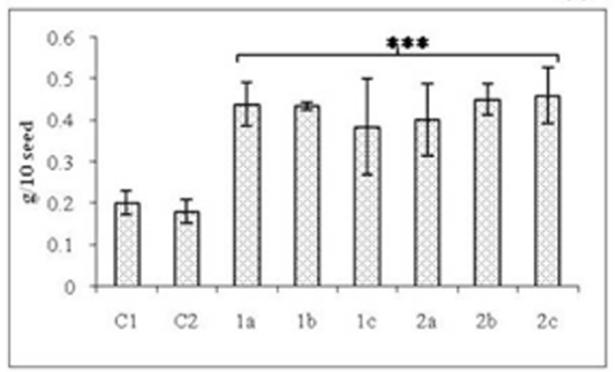

(c)

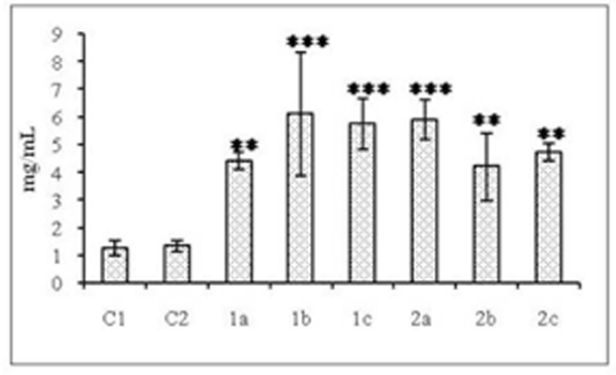

(e)

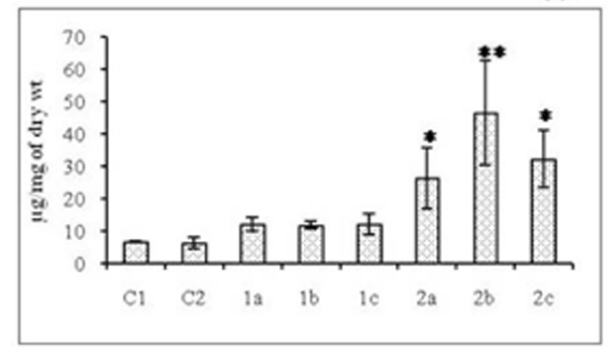

(b)

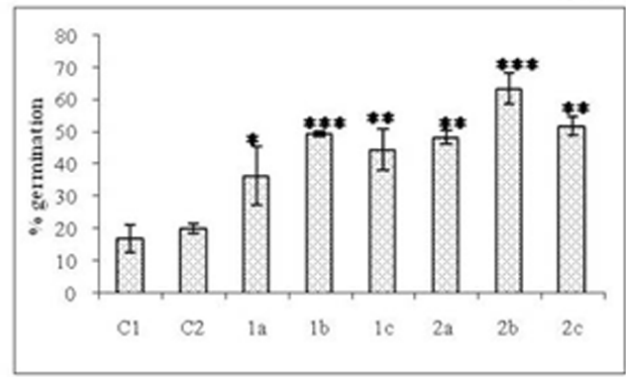

(d)

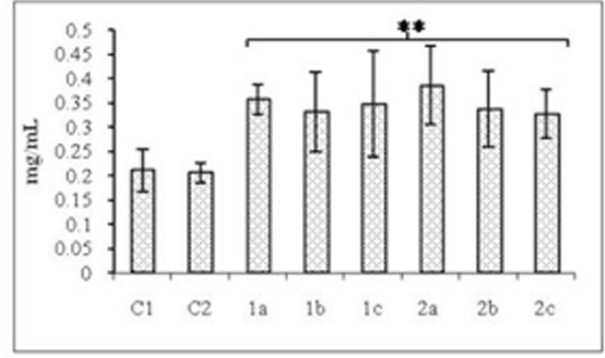

(f)

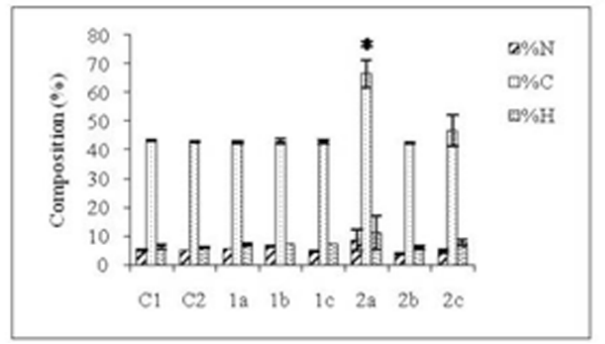

Figure 6. Quantitative analysis of seeds harvested from control and treated plants. (A) Seed biomass; (B) percent seed germination; (C) total protein content; (D) carbohydrate content; (E) Zinc content and (F) elemental analysis (C,H and N) \{*** indicates $P<0.001$, ** indicates $P<0.01 \& *$ indicates $P<0.05$ versus controls (C1 and $\mathrm{C} 2)$ \}

\subsection{Seed analysis}

Apart from various plant growth and development parameters, the effect of strain Psd inoculation in soil was also monitored in the harvested grains in terms of their yield and nutritional value. Increased seed biomass, indicative of good crop yield, was obtained in all Psd-treated sets (Figure 6A). Also seeds from treated plants appeared healthier and fuller compared to controls, based on grain morphology. As is indicated, the deficiency of $\mathrm{Zn}$ in soil affected the seed germination which was only $17 \%$ in untreated control. On the other hand, $\mathrm{Zn}$ fortification by $P$. fluorescens Psd led to increased percent germination, ranging from $35-65 \%$ in different sets (Figure $6 \mathrm{~B}$ ). In addition, plants growing in soil inoculated with strain 
Psd showed higher seed protein and carbohydrate content compared to control plants (Figure 6C \& D). Higher seed $\mathrm{Zn}^{2+}$ was also detected in the treated sets (Figure 6E). The $\mathrm{Zn}^{2+}$ levels were found higher in case of set 2 plants, where $\mathrm{Zn}$ source was industrial ore tailings. The composition of Carbon, Hydrogen, and Nitrogen in seeds was found to be largely unaffected by the treatments. However, an abundance of carbon was found in all the seeds (45-65\%) whereas, the percent composition of Nitrogen and Hydrogen ranged between 5-10\% (Figure 6F). Overall, PGPR inoculation in soil did not induce significant differences in the CHN levels between treated and control plants.

\section{Discussion}

PGPR, including Pseudomonas fluorescens, have substantial effects on plant growth, development and physiology by a combination of direct and indirect mechanisms (Upadhyay and Srivastava 2008). In the present investigation, we report the $\mathrm{Zn}^{2+}$ biofertilization of soil mediated by $P$. fluorescens strain Psd and its effect on growth and yield of T. aestivum var. HD2851. The strain was capable of solubilising $\mathrm{ZnO}$ in medium which made it a suitable candidate for application in contaminated environments where $\mathrm{Zn}^{2+}$ may be present in bound and unavailable forms. In vitro $\mathrm{Zn}^{2+}$ solubilisation ability of other bacteria, including Pseudomonas and Bacillus species have been reported by Saravanan et al (2003). Additionally, inoculation of other PGPR species of Burkholderia and Acinetobacter led to improved growth and yield of rice by zinc solubilisation and IAA production (Vaid et al. 2014). Solubilisation process was also followed by a drop in $\mathrm{pH}$, signifying the production of organic acids since glucose was provided as the carbon source to the bacterium. This was in consonance to the results obtained by Di Simine et al. (1998), where zinc phosphate solubilization by $P$. fluorescens was accompanied by production of gluconic acid and 2-keto gluconic acid. Present study also corroborated the fact that strain Psd acts as a potent bioleaching agent in metal recovery from ore-tailings. Although widely-used candidates for bioleaching processes are chemoautotrophic acidophilic bacteria, there are some reports that indicate towards the efficacy of Pseudomonas sp. in bioleaching processes (Pradhan and Kumar 2012).

Practical implication of PGPR inoculation in soil is based on the maintenance of effective cell population in rhizosphere (Viveros et al. 2010). During this study, application of $P$. fluorescens strain Psd in the form of a talc-based carrier formulation aided in better survival of the strain. Strain was able to maintain the cell density of approximately $10^{8} \mathrm{cfu} / \mathrm{mL}$ for 4 weeks, though a decline of $10^{4}$ fold was observed after $10^{\text {th }}$ week. This fluctuation might be the result of competition of $P$. fluorescens strain Psd with other soil microflora and the physical environmental conditions, since the pots were exposed to external environment. Micronutrient availability plays a crucial role in ascertaining better seedling growth. Lower levels of supplemented zinc (upto $25 \mathrm{mgL}^{-1}$ ) resulted in increased percent seed germination in Cyamopsis tetragonoloba but further increase in zinc concentration led to drop in germination (Manivasagaperumal et al. 2011). In Zea mays, concentrations of zinc upto $12 \mathrm{ppm}$ in the medium did not have any effect on seed germination and further growth of seedling (Mahmood et al. 2005). In the present study, zinc concentration in soil was found to be conducive for plant growth and, moreover, the presence of a plant growth promoting rhizobacterial strain aided in better seedling growth. 
PGPR, in general, are known to have a stimulatory effect on chlorophyll and protein content of leaves (Stefan et al. 2013) and other parameters like growth of roots and shoots (Mahmood et al. 2005). Present report shows an enhancement in growth of plants was detected in all the treated sets though we have not found any increase in the levels of protein and chlorophyll content. This can be attributed to the fact that the presence of heavy metals may prove detrimental for these parameters as was shown by Bonnet et al. (2012) in ryegrass. However, the effect was possibly nullified by the presence of strain Psd and hence, no significant differences were observed. In this study, increased activities of Zinc-containing enzymes like superoxide dismutase (SOD), carbonic anhydrase (CA), alkaline phosphatase were obtained in wheat leaves after bacterial zinc supplementation of the soil. Similar results were reported by Kleckerova et al. (2011). Apart from the activities of enzymes where $\mathrm{Zn}$ is directly involved, the antioxidant enzymes namely glutathione reductase and peroxidase were also quantified. Activity levels of these enzymes were found to be low in all the treated sets when compared to uninoculated controls. Increased production of these anti-oxidant enzymes in control sets may be one of strategies by which plants combat the stress posed by Zn-deficiency in soil. However, within the sets, an increase in the enzyme activities till $6^{\text {th }}$ week was followed by a decrease at $9^{\text {th }}$ week. This may be explained by the fact that these antioxidant enzymes carry out $\mathrm{H}_{2} \mathrm{O}_{2}$ detoxification during periods of high metabolic activity in plants. Similar results were reported in Phaseolus coccineus L. plants treated with Bacillus strains (Stefan et al., 2013).

An important determinant in biofertilization of cereal crops is the mobilization of micronutrient to edible parts of the plant (Palmgren et al. 2008). When grown in $\mathrm{Zn}$-deficient soils, $\mathrm{Zn}$ levels in wheat have been reported between $5-12 \mathrm{mg} / \mathrm{kg}$ (Erdal et al. 2002). In the present report, $\mathrm{Zn}$ biofortification mediated by P. fluorescens strain Psd resulted in $\sim 85 \%$ increase in grain $\mathrm{Zn}^{2+}$ concentrations. In addition, beneficial effect of zinc-laden biomass of $P$. fluorescens strain Psd was also reflected in grain yield and nutritional quality. Higher biomass, carbohydrate and protein content were obtained in case of seeds from the plants harvested from strain Psd inoculated soil.

\section{Conclusion}

Our study demonstrates the efficacy of zinc-laden biomass of plant growth promoting rhizobacterial strain P. fluorescens Psd in biofertilization of wheat. The plant-microbe interactions were affected by the micronutrient availability in soil, thus aiding in the zinc-fortification of wheat crop.

\section{References}

Abou-Shanab, RI., Angle, J.S., Delorme, T.A., Chaney, R.L., van Berkum, P., Moawad, H., Ghanem, K., Ghozlan, H.A. 2003. Rhizobacterial effects on nickel extraction from soil and uptake by Alyssum murale. New Phytologist. 158, 219224.

Arnon, D. I. 1949. Copper enzymes in isolated chloroplast polyphenol oxidase in Beta vulgaris. Plant physiol. 24, 1-15.

Bonnet, M., Camares, O., Veisseire, P. 2000. Effects of zinc and influence on Acremonium lolii on growth parameters, chlorophyll a fluorescence and antioxidant enzyme activities of ryegrass (Lolium perenne L. Cv Apollo). J. Exp. Bot. 51(346):945-953. 
Di Simine, C.D., Sayer, J.A., Gadd, G.M. 1998. Solubilization of zinc phosphate by a strain of Pseudomonas fluorescens isolated from a forest soil. Biol Fertil Soils. 28, 87-94.

Erdal. I., Yilmaz, A., Taban. S., Ekar, S., Torun, B., Cakmak, I. 2002. Phytic acid and phosphorus concentrations in seeds of wheat cultivars grown with and without zinc fertilization. Journal of Plant Nutrition. 25, 113-127.

Fasim. F., Ahmed, N., Parsons, R., Gadd, G.M. 2002. Solubilization of zinc saltes by a bacterium isolated from air environment of a tannery. FEMS Microbiol. Lett. 213, 1-6.

Gilotra, U., Srivastava, S. 1997. Plasmid-bound copper sequestration in Pseudomonas pickettii strain US321. Curr. Microbiol. 34, 378-381.

Gugi, B., Orange, M., Hellio, F., Burini, J.F., Guillou, C., Leriche, F., Guespin-Michel, J.F. 1991. Effect of growth temperature on several exported enzyme activities in the psychrotrophic bacterium Pseudomonas fuorescens. J. Bacteriol. 173, 38143820.

Hacisalihoglu, G., Hart, J.J., Wang, Yi-H., Cakmak, I., Kochian, L.V. 2003. Zinc Efficiency Is Correlated with Enhanced Expression and Activity of ZincRequiring Enzymes in Wheat. Plant Physiol. 131, 595-602.

Hafeez, B., Khanif, Y.M., Saleem, M. 2013. American Journal of Experimental Agriculture. 3, 374-391.

Jaworski, E.G. 1971. Nitrate reductase assay in intact plant tissue. Biochem Biophys. Res. Commun. 43, 1274-1279.

Kakkar, P., Das, B., Viswanathan, P.N. 1984. A modified spectrophotometric assay of superoxide dismutase. Indian J Biochem Biophys. 21, 130132.
Kleckerova, A., Sobrova, P., Krystofova, O., Sochor, J., Zitka, O., Babula, P., Adam, V., Docekalova, H., Kizek, R. 2011. Cadmium(II) and Zinc(II) Ions Effects on Maize Plants revealed by Spectroscopy and Electrochemistry. Int. J. Electrochem. Sci. 6, 6011-6031.

Mahmood, S., Hussain, A., Saeed, Z., Athar, M. 2005. Germination and seedling growth of corn (Zea mays $L$.) under varying levels of copper and zinc. Int. J. Environ. Sci. Tech. 2, 269-274.

Manivasagaperumal, R., Balamurugan, S., Thiyagarajan, G., Sekar, J. 2011. Effect of zinc on germination, seedling growth and biochemical content of cluster bean (Cyamopsis tetragonoloba (L.) Taub. Curr. Botany. 2, 11-15.

Martínez-Viveros, O., Jorquera, M.A., Crowley, D.E., Gajardo, G., Mora, M.L. 2010. Mechanisms and practical considerations involved in plant growth promotion by rhizobacteria. J Soil Sci. Plant Nutr. 10 (3): $293-319$.

Ohki, K. 1976. Effect of zinc nutrition on photosynthesis and carbonic anhydrase activity in cotton. Physiol. plantarum. 38, 300-304.

Palmgren, M.G., Clemens, S., Williams, L.E., Kramer, U., Borg, S. 2008. Zinc biofortification of cereals: Problems and solutions. Tre Plant Sci. 13, 464-473.

Pradhan, J.K., Kumar, S. 2012. Metals bioleaching from electronic waste by Chromobacterium violaceum and Pseudomonads sp. Waste Manag. Res. 30, 11511159.

Rao, M.V., Paliyath, G., Ormrod, D.P. 1996. Ultraviolet-B- and ozoneinduced biochemical changes in antioxidant enzymes of Arabidopsis thaliana. Plant Physiol. 110, 125-136. 
Rashid, A., Ryan, J. 2008. Micronutrient constraints to crop production in the Near East: Potential significance and management strategies. In: Micronutrient Deficiencies in Global Crop Production ed: Alloway, B.J. Springer Netherlands pp149-180.

Reddy, V.P., Faubion, J.M., Hosney, R.C. 1986. Odour generation in ground, stored pearl millet. Cereal Chemistry. 63, 403-406.

Saravanan, V.S., Subramoniam, S.R., Raj, S.A. 2003. Assessing in vitro solubilization potential of different zinc solubilizing bacterial (zsb) isolates. Brazilian Journal of Microbiology. 34. 121-125.

Smith, K.S., Ferry, J.G. 1999. Prokaryotic carbonic anhydrases. FEMS Microbiology Reviews. 24, 335-366.

Stefan, M., Munteanu, N., Stoleru, V., Mihasan, M. 2013. Effects of inoculation with plant growth promoting rhizobacteria on photosynthesis, antioxidant status and yield of runner bean. Romanian Biotechnological Letters. 18, 81328143.

Upadhyay, A., Srivastava, S. 2008. Characterization of a new isolate of Pseudomonas fluorescens strain Psd as a potential biocontrol agent. Lett. Appl. Microbiol. 47, 98-105.

Upadhyay, A., Srivastava, S. 2010. Evaluation of multiple plant growth promoting traits of an isolate of Pseudomonas fluorescens strain Psd. Indian J. Exp. Biol. 48, 601-609.
Upadhyay, A., Srivastava S. 2014. Mechanism of zinc resistance in a plant-growth promoting Pseudomonas fluorescens strain. World J. Microbiol. Biotechnol. 30. 2273-2282.

Vaid, S.K., Kumar, B., Sharma, A., Shukla, A.K., Srivastava, P.C. 2014. Effect of zn solubilizing bacteria on growth promotion and Zn nutrition of rice. J Soil Sci Plant Nutr. 14 (4), 889-910.

Vidhyasekaran, P., Muthamilan, M. 1995. Development of formulations of Pseudomonas fluorescens for control of chickpea wilt. Plant disease. 79, 782-786

Viveros, O.M., Jorquera, M.A., Crowley, D.E., Gajardo, G., Mora, M.L. 2010. Mechanisms and practical considerations involved in plant growth promotion by rhizobacteria. J. Soil Sci. Plant Nutr. 10, 293-319.

Whiting, S.N., de Souza, M.P., Terry, N. 2001. Rhizosphere bacteria mobilize $\mathrm{Zn}$ for hyperaccumulation by Thlaspi caerulescens. Environmental Science and Technology. 15, 3144-3150.

Zhuang, X.L., Chen, J., Shim, H., Bai, Z. 2007. New advances in plant growth-promoting rhizobacteria for bioremediation. Environ. Int. 33, 406-413. 